\title{
Action Mode of Gut Motility, Fluid and Electrolyte Transport in Chronic Constipation
}

\author{
Qi Zhao, Yan-Yan Chen*, Ding-Qiao Xu, Shi-Jun Yue, Rui-Jia Fu, Jie Yang, Li-Ming Xing and \\ Yu-Ping Tang *
}

Key Laboratory of Shaanxi Administration of Traditional Chinese Medicine for TCM Compatibility, and State Key Laboratory of Research and Development of Characteristic Qin Medicine Resources (Cultivation), and Shaanxi Key Laboratory of Chinese Medicine Fundamentals and New Drugs Research, Shaanxi University of Chinese Medicine, Xi'an, China

\section{OPEN ACCESS}

Edited by:

Jan Tack,

University Hospitals Leuven, Belgium

Reviewed by:

Raquel Abalo,

Rey Juan Carlos University, Spain Oksana Zayachkivska,

Danylo Halytsky Lviv National Medical

University, Ukraine

*Correspondence:

Yan-Yan Chen chenyanyan59@163.com

Yu-Ping Tang

yupingtang@sntcm.edu.cn

Specialty section: This article was submitted to Gastrointestinal and Hepatic Pharmacology,

a section of the journal

Frontiers in Pharmacology

Received: 17 November 2020 Accepted: 28 June 2021 Published: 27 July 2021

Citation:

Zhao Q, Chen Y-Y, Xu D-Q, Yue S-J, Fu R-J, Yang J, Xing L-M and Tang $Y-P$ (2021) Action Mode of Gut Motility,

Fluid and Electrolyte Transport in Chronic Constipation.

Front. Pharmacol. 12:630249. doi: 10.3389/fphar.2021.630249
Chronic constipation is a common gastrointestinal disorder, with a worldwide incidence of $14-30 \%$. It negatively affects quality of life and is associated with a considerable economic burden. As a disease with multiple etiologies and risk factors, it is important to understand the pathophysiology of chronic constipation. The purpose of this review is to discuss latest findings on the roles of gut motility, fluid, and electrolyte transport that contribute to chronic constipation, and the main drugs available for treating patients. We conducted searches on PubMed and Google Scholar up to 9 February 2021. MeSH keywords "constipation", "gastrointestinal motility", "peristalsis", "electrolytes", "fluid", "aquaporins", and "medicine" were included. The reference lists of searched articles were reviewed to identify further eligible articles. Studies focusing on opioid-induced constipation, evaluation, and clinic management of constipation were excluded. The occurrence of constipation is inherently connected to disorders of gut motility as well as fluid and electrolyte transport, which involve the nervous system, endocrine signaling, the gastrointestinal microbiota, ion channels, and aquaporins. The mechanisms of action and application of the main drugs are summarized; a better understanding of ion channels and aquaporins may be helpful for new drug development. This review aims to provide a scientific basis that can guide future research on the etiology and treatment of constipation.

Keywords: pharmacological treatment, pathophysiology, gut motility, fluid and electrolyte transport, chronic constipation

\section{INTRODUCTION}

Chronic constipation is a common gastrointestinal condition that is characterized by a high incidence rate, complex etiology, and difficult treatment. It can manifest as abdominal pain or bloating, or more commonly as chronic symptoms such as difficulty passing stools, infrequent stools, or incomplete defecation. Sometimes it can last for weeks, months, or years (Lacy et al., 2016). The prevalence of chronic constipation is increasing due to changes in diet composition, accelerated pace of life, and the influence of complex social and psychological factors. Epidemiological surveys have shown that the incidence of chronic constipation is between 14 and $30 \%$ worldwide, affecting individuals of all ages, races, socioeconomic status, and nationalities (Camilleri et al., 2017). However, it is perceived as being less frequent and not serious, and is often overlooked. Chronic constipation negatively impacts on quality of life, causing abdominal pain, bloating, loss of appetite and/or nausea, headaches, bad breath, restlessness, anxiety and/or depression, and is associated with 


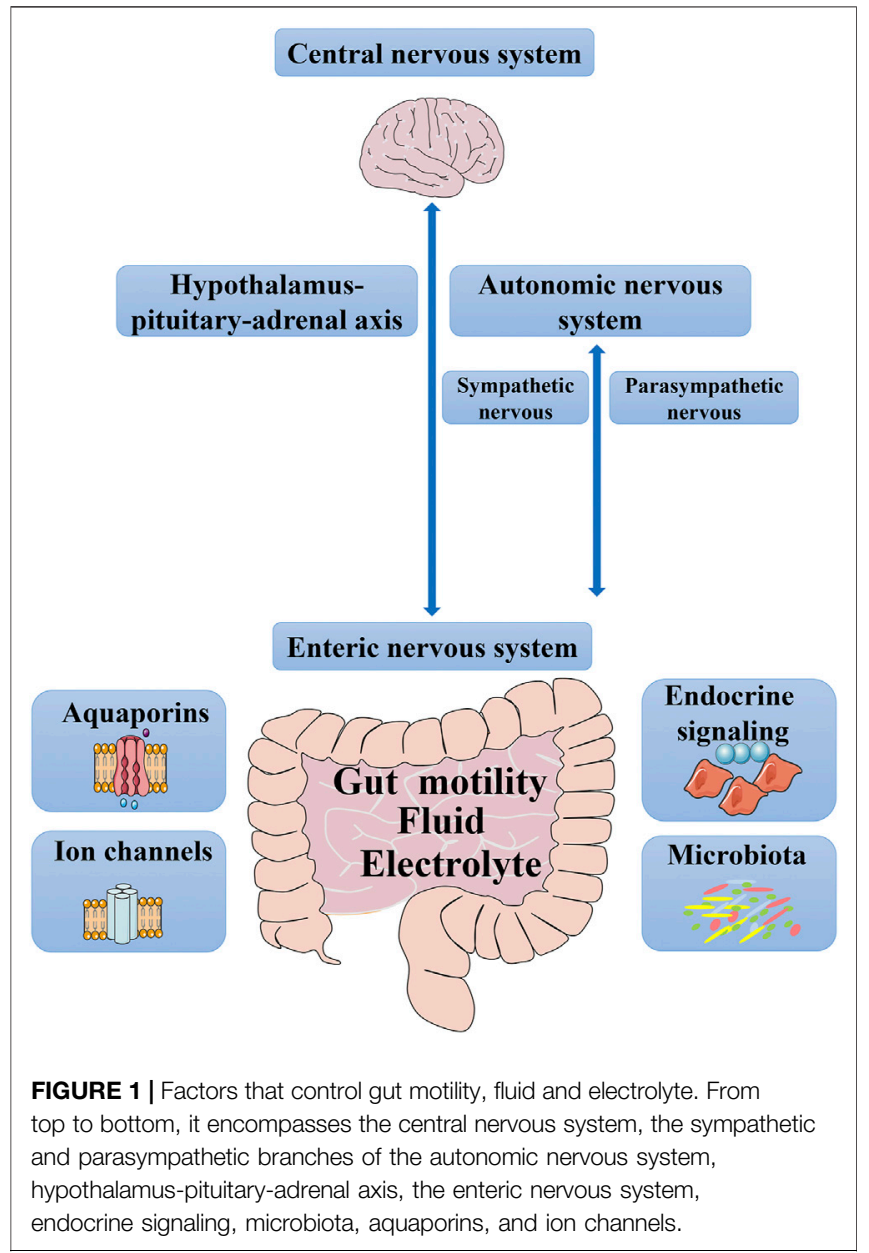

a substantial economic burden to individuals and society (Peery et al., 2019). The annual healthcare cost for patients with chronic constipation was reported to be $\$ 11,991$ in the United States. The direct costs are substantial and include outpatient services (44.8\%), inpatient hospitalizations (33.9\%), prescriptions (17.8\%), and emergency department visits (3.5\%) (Cai et al., 2014). The economic burden of chronic constipation includes the costs of medical treatment or hospitalization, as well as those associated with treatment failure, which increase both healthcare resource utilization and medical costs (Guerin et al., 2014).

The mechanisms, evaluation, and management of chronic constipation were recently reviewed. The main mechanisms discussed were colonic sensorimotor dysfunction and alteration of the microbiome (Bharucha and Lacy, 2020). However, the pathogenesis of chronic constipation is multifactorial and includes colonic motility and fluid transport, anorectal movement and sensory functions, as well as dietary and behavioral factors. The purpose of this review is to introduce the latest findings on the role of gut motility and fluid and electrolyte absorption and secretion in the development of chronic constipation.

Chronic constipation is the earliest manifestation of gastrointestinal hypomotility, which is characterized by significantly prolonged intestinal transit time (Wang, 2015).
Slower colonic transport prolongs the retention of intestinal contents and increases the reabsorption of water and electrolytes, resulting in a reduced volume and hardening of stools. Several factors jointly regulate gut motility, fluid, and electrolytes: the enteric nervous system (ENS), autonomic nervous system (ANS), central nervous system (CNS), endocrine signaling, microbiota, ion channels, and aquaporins (AQPs) (Figure 1). An imbalance or dysfunction in any of these components may cause abnormal intestinal function, which can lead to symptoms of constipation. First, gut motility and its influencing factors have been summarized, and then water and electrolyte transport will be discussed, focusing on the complexity of AQPs and ion channels. In terms of intestinal movement, one mechanism is neural networks, which control ENS independently, and the other involves the ANS and CNS. When it comes to fluid and electrolyte, we have mainly focused on channels, such as ion channels and AQPs. Finally, medication for treating chronic constipation has been discussed. Increasing motility and water secretion are currently the main goals of treatment for constipation; therefore, laxatives, which affect gut motility and water absorption/secretion, will be highlighted. Understanding the regulatory mechanism of gut motility and fluid and electrolytes transport in chronic constipation is helpful for further pathophysiological exploration and to provide a necessary theoretical basis for the further use of safe and effective drugs.

\section{GUT MOTILITY PATTERN}

In most cases, chronic constipation is considered to be closely related to disorders of gut motility (Wang, 2015). Two main types of intestinal movement enable feces to enter the rectum: peristalsis and colonic propulsion. These movements ensure the regular contraction of the colon wall and enable the contents to advance, thus promoting the normal excretion of feces.

\section{Peristalsis}

Peristalsis is the basis of most gastrointestinal propulsion movements, mainly in the colon, and includes the coordinated contraction and relaxation of the intestinal muscle layer (Camilleri et al., 2017). Relaxation/inhibition and contraction/ excitement are thought to spread along the intestinal tract following stimulation. The neural control hierarchy for peristalsis is as follow: the primary regulator is the ENS, followed by the ANS and then the CNS. Additionally, neurotransmitters, gastrointestinal hormones, and microbiota work together to modulate peristalsis. Factors that modulate peristalsis are shown in Figure 2.

\section{Regulation by ENS}

The exertion of intestinal motor function is largely achieved by regulation of the ENS, which acts independently from the CNS and is a highly autonomous gastrointestinal neural network mainly composed of enteric neurons and enteric glial cells (EGCs) (Avetisyan et al., 2015). Enteric neurons include 


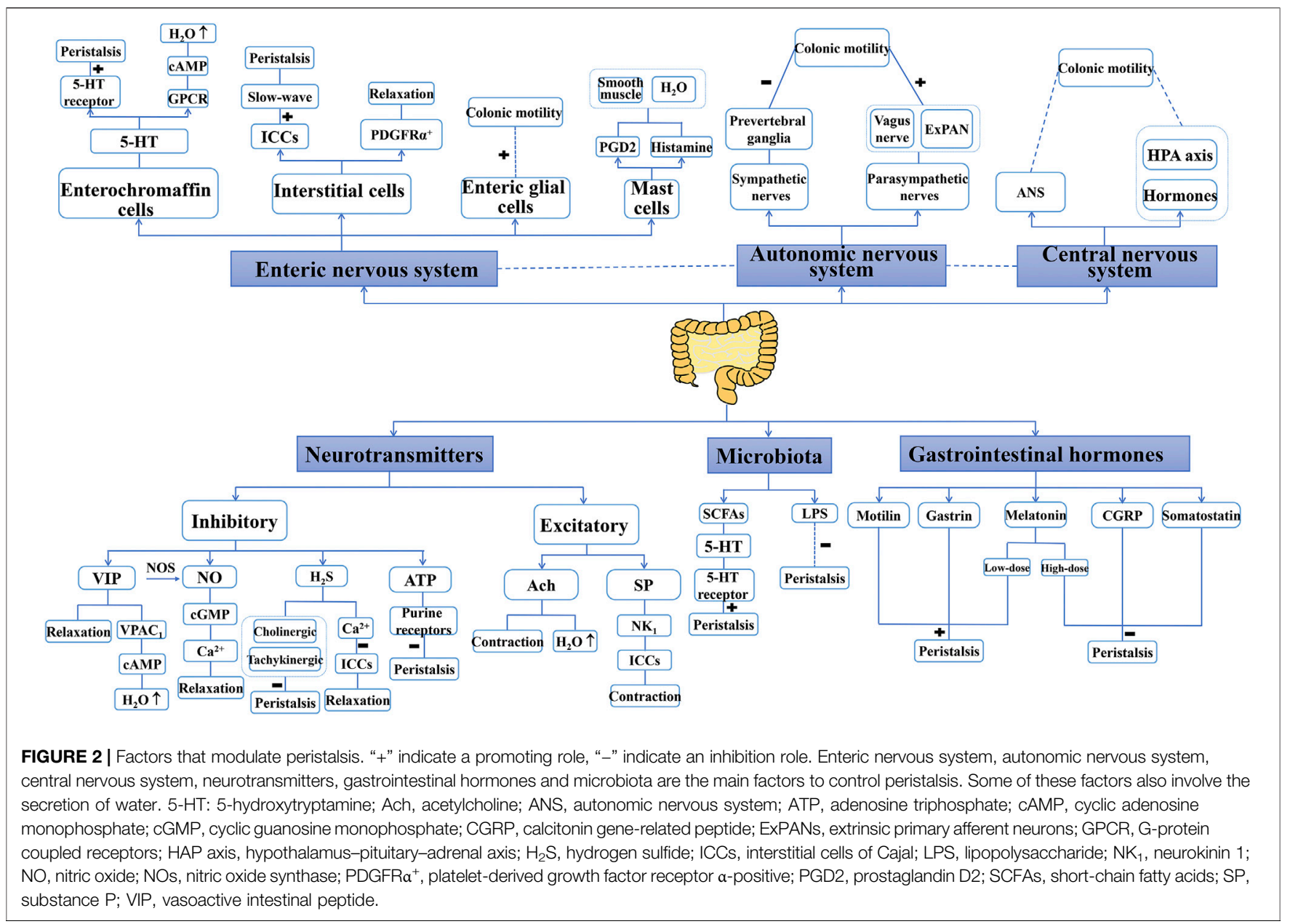

afferent neurons, interneurons, motor neurons, mechanosensitive neurons, etc., which are connected in peristalsis reflex circuitries (De et al., 2004). They extend process to communicate with diverse cells types including other enteric neurons, enterochromaffin cells (ECs), interstitial cells, and mast cells (Furness, 2000). EGCs are distributed inside and outside the nerve plexus (between the submucosal nerve plexus and the lamina propria), which can interact with intestinal neurons or directly participate in the regulation of gut motility (Aubé et al., 2006). EGCs help to promote the normal regulation of intestinal electric ion transport and secretory motor function (Grubišić and Gulbransen, 2017).

Peristalsis can be activated by chemical and/or mechanical stimuli that are sensed by ECs (Gershon and Tack, 2007). Most 5hydroxytryptamine (5-HT) in the human body is secreted by ECs. $5-\mathrm{HT}$ is a mediator involved in regulating a variety of physiological functions in the gastrointestinal tract and plays an important role in regulating gut motility and intestinal secretion (Reynaud et al., 2016). 5-HT can activate the peristaltic reflex by activating the 5-HT receptor on the mucosal end of the intrinsic primary afferent neurons, including $5-\mathrm{HT}_{2 \mathrm{~B}}, \quad 5-\mathrm{HT}_{3}, \quad 5-\mathrm{HT}_{4}$ and $5-\mathrm{HT}_{7}$ receptors (Wouters et al., 2007; Smith et al., 2014). These receptors signals through the myenteric plexus, which induces a wave of intestinal smooth muscle contraction. And the propulsion requires activation of both ascending excitatory neurons and descending inhibitory neurons. 5-HT also binds to G-protein coupled receptors in enterocytes (except for $5-\mathrm{HT}_{3}$ receptors), increasing the levels of cyclic adenosine monophosphate (cAMP) in target cells (Smith et al., 2014). An increase in cAMP causes the cystic fibrosis transmembrane conductance regulator (CFTR) to open, leading to $\mathrm{Cl}^{-}$and water outflow (Dawson, 1991). Accordingly, the regulation of 5-HT can have profound effects on gut motility and intestinal secretion.

Interstitial cells produce and transmit electrical signals that regulate the excitement and inhibition of smooth muscle. Two types of interstitial cells are involved: interstitial cells of Cajal (ICCs) and platelet-derived growth factor receptor a positive $\left(\mathrm{PDGFRa}^{+}\right)$cells. Constipation may be related to changes in the structure and shape of ICCs (Cohen et al., 2017), which play a significant physiological role in gut motility. They form a network of cells around the myenteric plexus between the circular and longitudinal muscle layers of the entire intestine and are responsible for regulating the contraction of gastrointestinal smooth muscle (Komuro, 2006). The pacing activity induced by ICCs causes a rhythmic slow-wave of smooth muscle cells. 
Slow-wave is a relatively regular periodic electrical activity, which controls the rhythm of intestinal contraction. ICCs integrate slow-wave activity with excitatory and inhibitory neurotransmission to orchestrate peristalsis. These findings demonstrated that disorders of gut motility are due to the loss of slow-wave activity as well as disturbed neurotransmission (Klein et al., 2013). PDGFRa ${ }^{+}$cells inhibit smooth muscle activity by activating purinergic receptors (Camilleri et al., 2017).

There are close apposed between axons and mast cells in the gastrointestinal mucosa (Stead et al., 1989). Mast cells can regulate peristalsis and fluid secretion via bidirectional braingut interactions between the ENS and the CNS (Schaeffer et al., 2012). Mast cells can stimulate excitatory neurons and activate the ENS network, and thereby promote powerful propulsive motility (Wang et al., 2014). Histamine and prostaglandin D2 released by mast cells have been shown to modulate the smooth muscle and fluid secretion (Wouters et al., 2016).

\section{Regulation by ANS and CNS}

The ANS, which includes the sympathetic and parasympathetic nervous systems, is a collection of afferent and efferent neurons that link the CNS with the ENS (Tait and Sayuk, 2021). Both sympathetic and parasympathetic nerves regulate gut motility by affecting the ENS circuit (Mayer et al., 2014). The postganglionic fibers of the sympathetic nerve are adrenergic nerve fibers which cause the release of norepinephrine that elicit the presynaptic inhibition of neurotransmitter release, thereby inhibiting intestinal motility. Meanwhile, the parasympathetic nerve mainly transmits excitation signals via the vagus nerve (Bonaz et al., 2018). Extrinsic primary afferent neurons (ExPANs) derived from spinal ganglia can regulate colon function. ExPANs regulate myenteric neuron activity and smooth muscle contraction via a parasympathetic spinal circuit (Smith-Edwards et al., 2019).

CNS modulates gastrointestinal motility via two distinct routes (Mayer and Tillisch, 2011). First, it modulates gut motility via the ANS. The vagus nerve is the main component of the parasympathetic nervous system, which can transmit intestinal-related signals to the CNS. Second, CNS signals induce gastrointestinal motility via hormonal pathways, including the hypothalamus-pituitary-adrenal axis, and hormones of the neuroendocrine stress response. For example, neurotensin released by central preganglionic neurons promotes the release of substance $\mathrm{P}$ (SP), which in turn stimulates peristalsis (Szurszewski et al., 2002).

\section{Regulation by Neurotransmitters}

Constipation is associated with abnormalities in intestinal neurotransmitters, which are a class of active small-molecule peptides produced in gastrointestinal endocrine cells and nerve cells. There are two type of neurotransmitters, inhibitory and excitatory ones, which play an important role in regulating the motility and secretion of the gastrointestinal tract (Schneider et al., 2019).

Inhibitory neurotransmitters include vasoactive intestinal peptide (VIP), nitric oxide (NO), adenosine triphosphate (ATP), and hydrogen sulfide $\left(\mathrm{H}_{2} \mathrm{~S}\right)$, which can induce smooth muscle relaxation and inhibit intestinal sensitivity. VIP, one of the most important neurotransmitters in the ENS, inhibits the contraction of intestinal circular muscle, maintaining the intestine in a state of relaxation, and may also participate in the secretion of intestinal fluid (Mourad and Nassar, 2000). VIP binds to its receptor $\left(\mathrm{VPAC}_{1}\right)$, leading to the excretion of cAMPrelated $\mathrm{HCO}_{3}{ }^{-}$. This causes $\mathrm{Na}^{+}$and $\mathrm{H}_{2} \mathrm{O}$ to enter the intestinal cavity, thus increasing fluid secretion (Chandrasekharan et al., 2013). Therefore, reduced VIP production may result in reduced fluid secretion, which is a possible cause of constipation or its aggravation. VIP can activate nitric oxide synthase (NOS) in the colon wall, leading to the production of the inhibitory neurotransmitter NO. NO activates cyclic guanosine monophosphate (cGMP)-dependent protein kinase by stimulating intracellular soluble guanylate cyclase, which reduces the level of intracellular $\mathrm{Ca}^{2+}$, relaxes smooth muscle cells, and eventually weakens gastrointestinal motility (Beck et al., 2019). $\mathrm{H}_{2} \mathrm{~S}$ is a gasotransmitter, which plays a role in the regulation of gut motility. In addition, it can inhibit the pacemaker activity of ICCs by regulating intracellular $\mathrm{Ca}^{2+}$, which in turn leads to relaxation of gastrointestinal smooth muscle (Parajuli et al., 2010). Furthermore, high concentrations of $\mathrm{H}_{2} \mathrm{~S}$ can inhibit gut motility by interacting with cholinergic and tachykinergic neural-mediated pathways (Martinez-Cutillas et al., 2015). ATP, an important neurotransmitter, inhibits peristalsis by acting on the purine receptors on intestinal nerves and muscles (Heinemann et al., 1999).

5-HT, acetylcholine (Ach), and SP are excitatory neurotransmitters, which can stimulate intestinal muscle contraction and promote intestinal peristalsis. 5-HT is a paracrine signaling molecule released from ECs, and also a neurotransmitter that produced by serotonergic neurons of the ENS (Gershon, 2012). Ach activates the gastrointestinal tract by stimulating muscle contraction and increasing the peristalsis of gastrointestinal smooth muscle. Additionally, the non-neuronal release of Ach from colonocytes, coupled with propionate stimulation, promote $\mathrm{Cl}^{-}$secretion, via the paracrine action of Ach on muscarinic receptors of colonocytes (Yajima et al., 2011). $\mathrm{SP}$ can regulate ICCs through the tachykinin $\mathrm{NK}_{1}$ receptor and exerts a strong contractile effect on gastrointestinal smooth muscle (Jun et al., 2004).

\section{Regulation by Gastrointestinal Hormones}

The ENS regulates gut motility through neurotransmitters and by the secretion of gastrointestinal hormones for humoral regulation. Motilin, gastrin, melatonin, calcitonin gene-related peptide (CGRP), and somatostatin have important physiological significance in the regulation of gastrointestinal motility (Penning et al., 2000). Motilin acts directly on the motilin receptor on gastrointestinal smooth muscle cells and stimulates gastrointestinal peristalsis (Xu et al., 2005). Gastrin can increase small intestinal motility (Ahmed and Ahmed, 2019). Melatonin acts on the muscularis mucosae or the myenteric plexus, is involved in regulating colonic motility, and has a bidirectional effect on gut motility (Esteban-Zubero et al., 2017). Low-dose melatonin has been shown to accelerate 
intestinal transit, while high-dose melatonin decreases gut motility. CGRP has been found to exert an inhibitory effect on gut motility by inducing interneurons to trigger the peristaltic reflex (Ceccotti et al., 2018). Somatostatin inhibits intestinal secretion, peristalsis, and the release of gastrointestinal hormones by acting on the somatostatin receptors on gastric smooth muscle (John and Chokhavatia, 2017).

\section{Regulation by Microbiota}

Studies have revealed an important relationship between the intestinal microbiota and constipation (Yarullina et al., 2020). Bacteroides were found to be more abundant in patients with chronic constipation (Yarullina et al., 2020), as well as decreased numbers of bifidobacteria and lactobacilli, compared with healthy controls (Dimidi et al., 2017). Short-chain fatty acids (SCFAs), endotoxin, and other products are produced during intestinal microbial metabolism and may affect gut motility (Segers et al., 2019). The intestinal microbiota can regulate the release of 5-HT by ECs, which in turn, affects gut motility (Yano et al., 2015). Furthermore, the release of 5-HT from ECs in response to SCFAs stimulates $5-\mathrm{HT}_{3}$ receptors located on vagal sensory fibers, resulting in muscle contraction (Fukumoto et al., 2003). Serum endotoxin activity was found to be positively related to constipation in patients undergoing chronic hemodialysis (Bossola et al., 2016). Involvement of the endogenous cannabinoid system in the regulation of gastrointestinal motility has been demonstrated in vitro and in vivo (Aviello et al., 2008). Lipopolysaccharide (LPS) was shown to reduce the amplitude and frequency of myoelectric spiking activity, and this was accompanied by a slowing of gastrointestinal transit (Li et al., 2010). Both cannabinoid-1 and cannabinoid-2 receptor antagonists were able to reverse the delayed intestinal transit induced by LPS (Li et al., 2010). However, evidence remains limited; therefore, further studies are needed to elucidate the exact mechanism.

\section{Colonic Propulsion}

Several forms of contraction (mass movements, retrograde propulsion, segmentation movement) push contents through the colon. Propulsive contraction is designed to push and eventually discharge feces. The large contraction of colonic smooth muscle cells increases the intracavitary pressure, which are termed high-amplitude propagating contractions (HAPCs), the main propulsive contractile force which represent the main motor pattern related to mass movement (Vijayvargiya and Camilleri, 2019). Another motor pattern generated by enteric nerves is segmentation, which involves alternating contractions of the muscularis in a given region without forward propulsion of the luminal contents. The rhythmic slow-wave pattern naturally organizes the contractile activity of gastrointestinal muscles into phasic contractions (Sanders et al., 2014). The contents of the colon can also move in a retrograde direction, which are more pronounced after a meal, and this pattern of movement can potentially prevent rectal filling (Lin et al., 2017). The decreased frequency of HAPCs, increased low-amplitude propagated contractions, and reverse propulsive contraction frequency are related to the occurrence of constipation (Bassotti et al., 2003; Dinning and Di, 2011).

\section{MECHANISM OF INTESTINAL ELECTROLYTE TRANSPORT}

Electrolyte imbalance can lead to muscle weakness, thus accelerating the occurrence of chronic constipation. The modulation of ion channels and exchangers in epithelial cells can promote intestinal secretion, thereby enhancing gastrointestinal transit and promoting fecal excretion. This is also the mechanism through which some drugs exert their laxative effect (Figure 3). Under normal physiological conditions, many ion channels and exchangers exist in the intestinal epithelium, which play an important role in maintaining the balance of intestinal absorption and secretion (Kagnoff, 2014). The main mechanisms associated with ion fluxes are nutrient-coupled $\mathrm{Na}^{+}$absorption, electroneutral $\mathrm{NaCl}$ absorption, electrogenic $\mathrm{Na}^{+}$absorption, and $\mathrm{Cl}^{-}$secretion (Kato and Romero, 2011).

\section{Mechanism of Intestinal Electrolyte Absorption Nutrient-Coupled $\mathrm{Na}^{+}$Absorption}

Enteral nutrient-coupled $\mathrm{Na}^{+}$absorption involves sodiumglucose transporters and Na-amino acid cotransporters, in which $\mathrm{Cl}^{-}$and fluid are absorbed via a paracellular pathway (Kato and Romero, 2011). This also occurs in the presence of an adverse osmotic gradient (Wright and Loo, 2000).

\section{Electroneutral $\mathrm{NaCl}$ Absorption}

The coupled $\mathrm{NaCl}$ absorption mechanism occurs in both the small intestine and colon and is mediated by the coupling activity of the anion exchange transporter SLC26A6 or $\mathrm{Cl}^{-}$anion exchanger SLC26A3 and the sodium/hydrogen exchanger family (NHE2 or NHE3) on the surface of epithelial cells (Patel-Chamberlin et al., 2016; Barrett, 2017). $\mathrm{Na}^{+}$and $\mathrm{Cl}^{-}$ enter the cell cytosol through these transporters, and are then transported across the basolateral membrane via the $\mathrm{Na}^{+} / \mathrm{K}^{+}$ATPase and $\mathrm{K}^{+} / \mathrm{Cl}^{-}$cotransporters. Studies have shown that inhibiting SLC26A3, thus, blocking intestinal fluid absorption, can be used to effectively treat the main types of constipation (Haggie et al., 2018).

\section{Electrogenic $\mathrm{Na}^{+}$Absorption}

Epithelial sodium channel $(\mathrm{ENaC})$ is present on the superficial epithelial cells of the distal colon and rectum. $\mathrm{Na}^{+}$absorption occurs on the luminal epithelial membrane through the $\mathrm{ENaC}$ and is compensated for by the $\mathrm{Na}^{+}$output of basolateral $\mathrm{Na}^{+} / \mathrm{K}^{+}$-ATPase. This mechanism is important in the distal colon (Barrett, 2017). CAP1/Prss8, an in vivo regulator of colonic $\mathrm{ENaC}$, can activate $\mathrm{ENaC}$ activity (Malsure et al., 2014) and is up-regulated by aldosterone. 


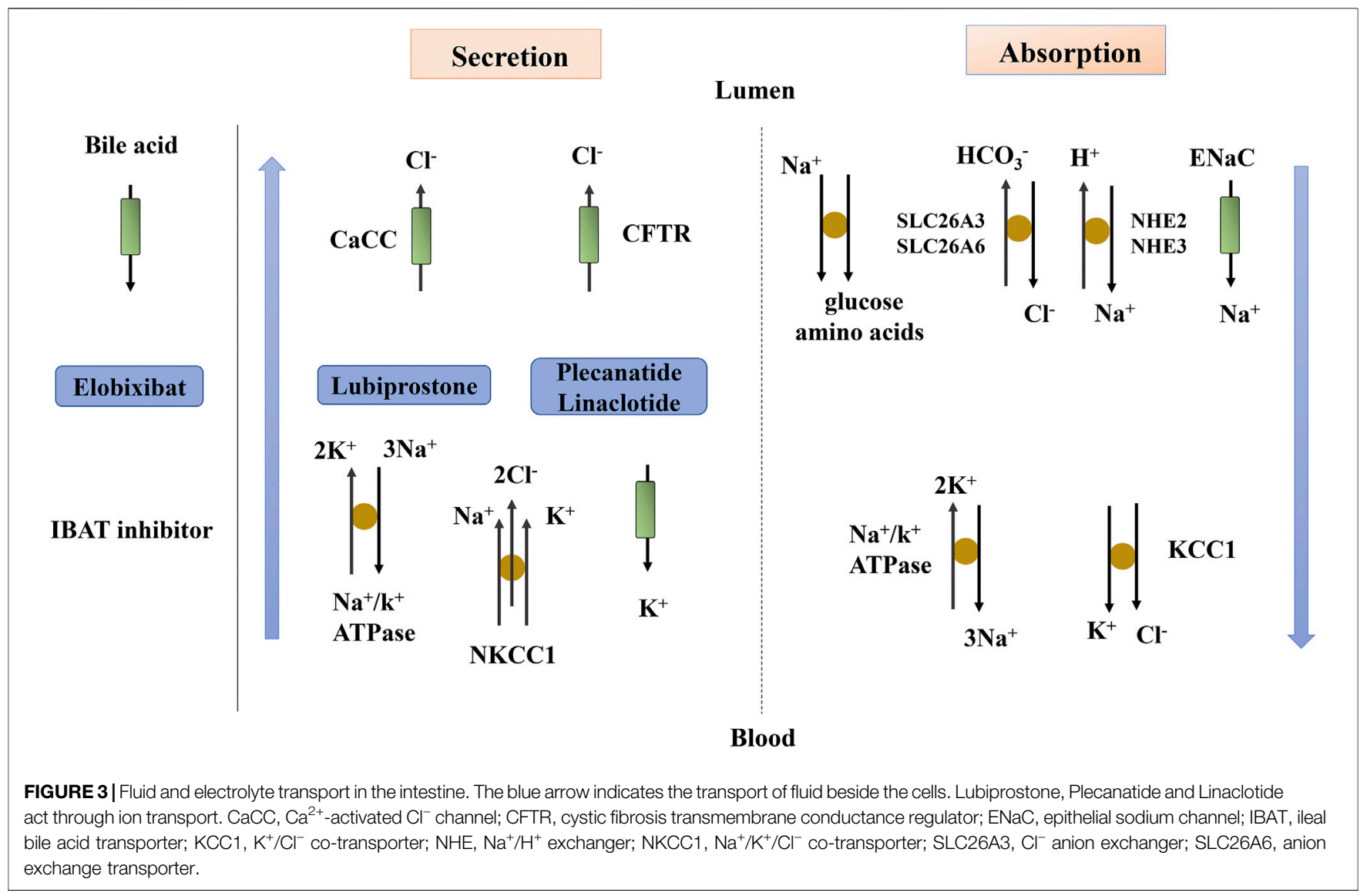

\section{Mechanism of Intestinal Electrolyte Secretion}

Chloride ion transport in epithelial cells is the main determinant of fluid secretion, and $\mathrm{Cl}^{-}$is mainly secreted by crypt cells in the whole small intestine and colon. The main $\mathrm{Cl}^{-}$channels involved in intestinal fluid secretion are CFTR and $\mathrm{Ca}^{2+}$-activated $\mathrm{Cl}^{-}$channels (CaCC). CFTR is a chloride channel regulated by cAMP and cGMP, which plays a leading role in intestinal secretion (Kunzelmann et al., 2019). The increase of cAMP causes the apical membrane CFTR to open, leading to $\mathrm{Cl}^{-}$outflow and intracellular depolarization (Dawson, 1991). Then, the increase in cAMP causes cAMPdependent $\mathrm{K}^{+}$channels in the basement membrane to open, resulting in $\mathrm{K}^{+}$outflow and intracellular hyperpolarization to counteract the depolarization caused by the opening of apical membrane CFTR (Kunzelmann et al., 2001). The decreased intracellular $\mathrm{Cl}^{-}$concentration induced by $\mathrm{Cl}^{-}$outflow enhances the activity of the $\mathrm{Na}^{+} / \mathrm{K}^{+} / 2 \mathrm{Cl}^{-}$co-transporter (NKCC1) in the basement membrane, transporting $\mathrm{Cl}^{-}$into the cell through the basement membrane. Driven by $\mathrm{Na}^{+} / \mathrm{K}^{+}$ATPase, NKCC1, and $\mathrm{K}^{+}$channels, $\mathrm{Cl}^{-}$enters the cell through the basement membrane, generating a $\mathrm{Cl}^{-}$gradient across the epithelial cell top membrane. The activation of CaCC causes $\mathrm{Cl}^{-}$outflow, and the secretion of $\mathrm{Cl}^{-}$drives water transport (Jakab et al., 2013; Camilleri et al., 2017).

\section{MECHANISM OF INTESTINAL FLUID TRANSPORT}

\section{Intestinal Fluid Transport Pathway}

Colonic water absorption is the final link of intestinal water absorption in the body, and constipation is closely related to a disorder in the colonic fluid transport system. Intestinal epithelial fluid can be transported via paracellular and transcellular routes. Colonocytes are linked by tight junctions that impede fluid movement. This limits cell bypass absorption, and cross-cell transport becomes the main pathway of colonic fluid absorption (Sundell and Sundh, 2012). The transcellular route involves free diffusion, co-transport, and AQPs pathways (Laforenza et al., 2005). Among these, AQPs, which act as a special channel for the rapid transport of water molecules and small molecular solutes, play an important role in maintaining liquid homeostasis.

\section{Aquaporins in the Intestinal Tract}

AQPs are a family of water channel molecules (AQP0-12) that promote the movement of water from areas of low permeability to areas of high permeability under the action of osmotic gradients (Sisto et al., 2019). AQPs are located on the cell membrane where they form channels to control the inflow and outflow of water. AQPs play a pivotal role in the regulation of intestinal absorption, 


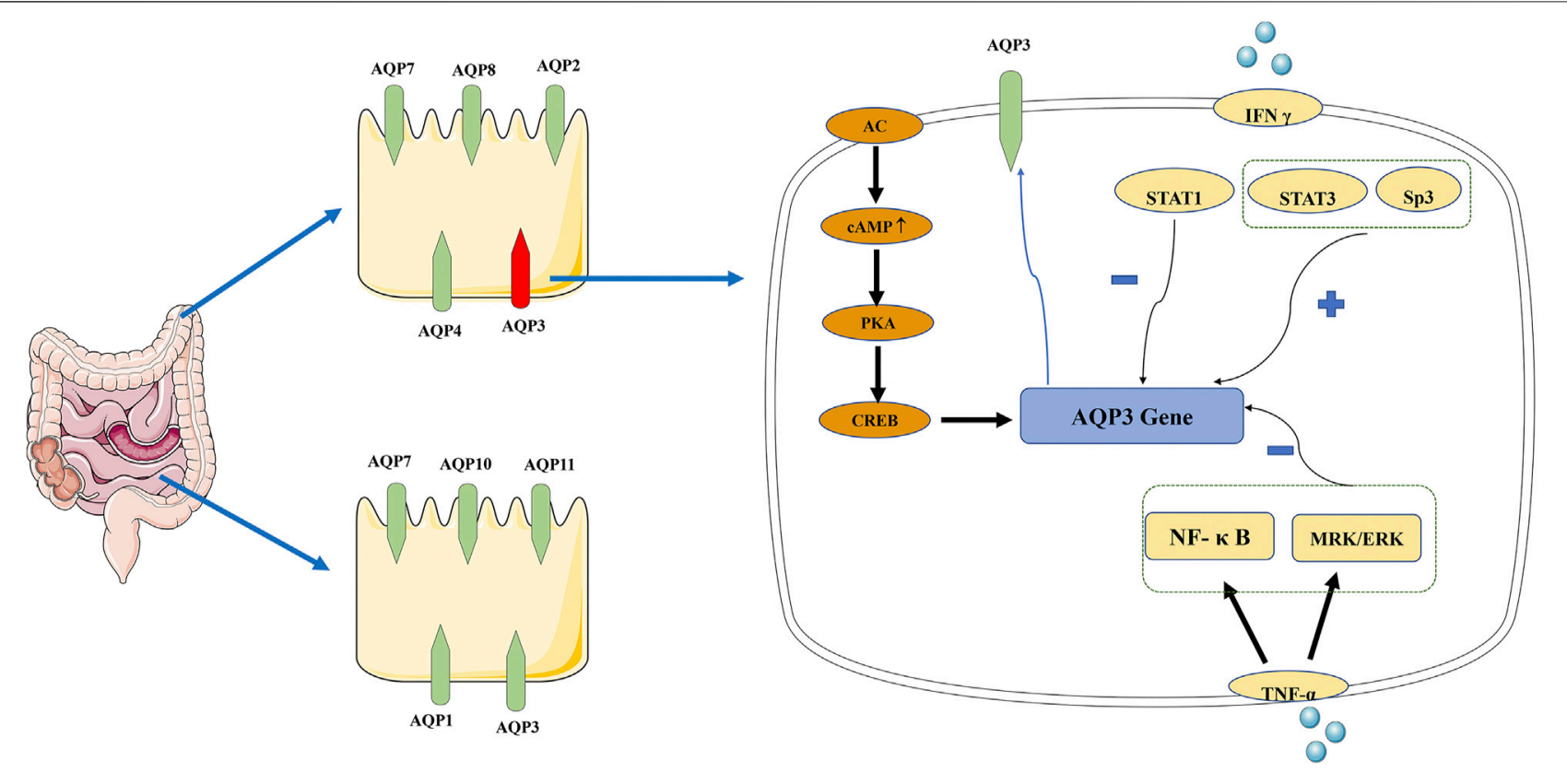

FIGURE 4 | Distribution of AQPs in intestinal tract and signal transduction mechanism of AQP3. AQP1, AQP3, AQP7, AQP10, and AQP11 are highly expressed in the small intestine, while AQP2, AQP3, AQP4, AQP7, and AQP8 are the main subtypes in the colon. "+" indicate a promoting role, "-" indicate an inhibition role. In AQP3 expression, there are two pathways: $\mathrm{AC}$-mediated short-time regulation and long-term regulation at the transcriptional level. $\mathrm{AC}$, adenylate cyclase; $\mathrm{AQP}$, aquaporin; cAMP, cyclic adenosine monophosphate; CREB, cAMP response element-binding protein; PKA, protein kinase A; TNF- $\alpha$, tumor necrosis factor alpha.

secretion, and water metabolism by mediating the transmembrane transport of water molecules.

Many studies have shown that AQP3 is a key subtype of colonic AQPs, and its expression level affects water transport in the intestinal tract. Up-regulation of AQP3 expression in colonic epithelial cells can lead to severe constipation (Zhu et al., 2017). AQPs can be regulated (Figure 4) through a change in their activity or number, which is also called short-term regulation. AQPs are targets of VIP that can change the content of AQPs on the cell membrane through the cellular protein kinase A (PKA) system to regulate the membrane permeability to water. VIP upregulates the expression of AQP3 and its mRNA by activating the cAMP-dependent PKA pathway (Itoh et al., 2003), blocking the movement of $\mathrm{Cl}^{-}$into the intestinal cavity and that of osmotic water from the cells to the cavity (Hamabata et al., 2002). PKA also phosphorylates cAMP response element-binding protein (CREB); the phosphorylated CREB then stimulates AQPs gene transcription (Ikeda and Matsuzaki, 2015).

The other mechanism refers to the increased AQPs synthesis, mRNA, and protein expression at the transcriptional level, which is termed long-term regulation. Studies have shown that AQPs promote intestinal function through mechanisms that may involve changes in signaling. NF- $\kappa \mathrm{B}$, a key signal in the longterm regulation of AQP3, down-regulates the expression of AQP3 (Zhan et al., 2020). Tumor necrosis factor alpha (TNF- $\alpha$ ) reduces the expression of AQP3 in HT-29 cells through MRK/ERK and NF- $\kappa B$ signaling (Peplowski et al., 2017). The binding of Sp3 transcription factor to the AQP3 promoter can partially prevent the down-regulation of AQP3 expression induced by TNF- $\alpha$. IFN- $\gamma$, a key factor of impaired epithelial transport and barrier function, can increase epithelial permeability by inhibiting the expression of AQP3. STAT1 has been shown to partially block the down-regulation of AQP3 expression induced by IFN- $\gamma$, while STAT3 and Sp3 can increase AQP3 expression (Peplowski et al., 2018).

A growing body of studies has investigated the importance of the gastrointestinal water transport system in intestinal function and the effect of AQPs on intestinal fluid secretion and chronic constipation. However, the mechanisms of AQPs action on intestinal fluid and constipation remain unclear. Further studies on the expression and function of AQPs in the intestinal tract and the mechanism of water transport should provide information for the development of new laxatives.

\section{ACTION MECHANISM OF DRUGS FOR TREATING CONSTIPATION}

With a better understanding of the mechanisms of chronic constipation and continued advances in pharmaceutical development, an expanding array of treatment approaches have been developed. At present, drugs are the mainstay for patients with chronic constipation. Many studies have reported the efficacy and safety of laxatives in patients with constipation. Intervention with laxatives can alter the intestinal environment by affecting gut motility, ion transport, and liquid absorption/ secretion, which are beneficial for patients with constipation. The main categories of approved drugs for the treatment of constipation are osmotic laxatives, stimulant laxatives, secretagogues, serotonergic agents, and ileal bile acid 
TABLE 1 | Summary of drugs for the treatment of constipation.

\begin{tabular}{|c|c|c|c|c|c|}
\hline Category & Medication & Dosage & $\begin{array}{l}\text { Possible side } \\
\text { effects }\end{array}$ & $\begin{array}{l}\text { Mechanism of } \\
\text { action }\end{array}$ & Molecular signal \\
\hline Bulking agents & $\begin{array}{l}\text { Insoluble fiber } \\
\text { Soluble fiber }\end{array}$ & $\begin{array}{l}25-30 \mathrm{~g} / \\
\text { day }\end{array}$ & Bloating & $\begin{array}{l}\text { Luminal water binding increases stool volume and soften } \\
\text { stool }\end{array}$ & $\begin{array}{l}\text { Not involved } \\
\text { Not involved }\end{array}$ \\
\hline \multirow[t]{3}{*}{ Osmotic laxatives } & Lactulose & $\begin{array}{l}15-25 \mathrm{ml} / \\
\text { day }\end{array}$ & Bloating, abdominal pain & $\begin{array}{l}\text { Produce the osmotic gradient in the cavity, increase the } \\
\text { moisture in the cavity and soften the stool }\end{array}$ & Not involved \\
\hline & $\begin{array}{l}\text { Polyethylene } \\
\text { glycol }\end{array}$ & $\begin{array}{l}10-20 \mathrm{~g} / \\
\text { day }\end{array}$ & $\begin{array}{l}\text { Abdominal distention, } \\
\text { diarrhea }\end{array}$ & & Not involved \\
\hline & $\mathrm{MgSO}_{4}$ & 5-20 g/day & $\begin{array}{l}\text { Electrolyte disorder, } \\
\text { diarrhea }\end{array}$ & & $\mathrm{Mg}^{2+} \uparrow \mathrm{cAMP} \uparrow \mathrm{AQP} 3 \uparrow$ \\
\hline \multirow[t]{2}{*}{ Stimulant laxatives } & Bisacodyl & $\begin{array}{l}5-10 \mathrm{mg} / \\
\text { day }\end{array}$ & $\begin{array}{l}\text { Abdominal cramps, } \\
\text { diarrhea. Abdominal pain }\end{array}$ & $\begin{array}{l}\text { Stimulate intestinal mucosa to secrete water and } \\
\text { electrolytes and accelerate peristalsis }\end{array}$ & TNF- $\alpha \uparrow P G E_{2} \uparrow A Q P 3 \downarrow$ \\
\hline & Senna, rhubarb & No RCTs & Melanosis coli & & $\mathrm{PGE}_{2} \uparrow \mathrm{AQP} 3 \downarrow \mathrm{AQP} 8 \downarrow$ \\
\hline \multirow[t]{3}{*}{ Secretagogues } & Lubiprostone & $\begin{array}{l}24-72 \mu g / \\
\text { day }\end{array}$ & Nausea, vomiting, diarrhea & Increase intestinal fluid secretion and soften stool & $\mathrm{Cl}^{-} \downarrow \mathrm{Na}^{+} \uparrow \mathrm{H}_{2} \mathrm{O} \uparrow$ \\
\hline & Plecanatide & 3 mg/day & Diarrhea & & $\mathrm{cGMP} \uparrow \mathrm{Cl}^{-} \downarrow$ \\
\hline & Linaclotide & $145 \mu \mathrm{g} /$ day & & & $\mathrm{Na}^{+} \uparrow \mathrm{H}_{2} \mathrm{O} \uparrow$ \\
\hline $\begin{array}{l}\text { Serotonergic } \\
\text { agents }\end{array}$ & Prucalopride & $2 \mathrm{mg} /$ day & $\begin{array}{l}\text { Diarrhea, headache, } \\
\text { nausea, abdominal pain }\end{array}$ & Selective action on 5 -HT receptor & $5-\mathrm{HT}_{4} \uparrow \mathrm{ICCs} \uparrow$ \\
\hline IBAT inhibitor & Elobixibat & $\begin{array}{l}5-15 \mathrm{mg} / \\
\text { day }\end{array}$ & Abdominal pain, diarrhea & $\begin{array}{l}\text { Increase the concentration of bile acid in colon and } \\
\text { promote fluid secretion }\end{array}$ & Bile acid $\uparrow \mathrm{Cl}^{-} \downarrow \mathrm{H}_{2} \mathrm{O} \uparrow$ \\
\hline $\begin{array}{l}\text { Motilin receptor } \\
\text { agonists }\end{array}$ & $\begin{array}{l}\text { Mitemcinal } \\
(\text { GM-611) }\end{array}$ & No RCTs & Not clear & Activation of motilin receptor and promote peristalsis & motilin $\uparrow$ \\
\hline TGP & Paeonia & No RCTs & Not clear & $\begin{array}{l}\text { Improve the function of ICCs and regulate } \\
\text { neurotransmitters to accelerate peristalsis }\end{array}$ & $I C C s \uparrow N O \downarrow N O S \downarrow V I P \downarrow$ \\
\hline
\end{tabular}

transporter inhibitors (Black and Ford, 2018). Drugs used for the treatment of chronic constipation are listed in Table 1. The goal of such medications is to promote fecal excretion and relieve constipation-related symptoms, and to improve the patients' quality of life. However, different drugs act via different pathways, and a further understanding of their mechanisms, combined with that of ion transport and the expression of AQPs, may lead to the development of promising drugs.

\section{Bulking Agents}

The American Gastroenterological Association recommends that use of a fiber supplement should be the initial treatment approach for constipation (Bharucha et al., 2013). Fiber is composed of high-molecular weight food components that cannot be degraded by intestinal enzymes thus it remains in the intestinal cavity and increases fecal volume. Insoluble fibers, such as wheat bran, may alter gut motility, thereby accelerating gastrointestinal transit and increasing the frequency of stools. Soluble fiber, such as psyllium, expands after absorbing water in the intestine, thus softening and increasing the volume of feces. Although fiber supplements are effective in the treatment of constipation, adverse reactions, such as bloating, are becoming a problem with long-term therapy (Wald et al., 2008).

\section{Osmotic Laxatives}

If patients do not respond to fiber, then osmotic laxatives should be considered. Osmotic laxatives are poorly absorbed or nonabsorbed substances, that produce intraluminal osmotic gradients, causing secretion of water and electrolytes into the lumen. This results in luminal water retention, an increase in stool water content and stool softening, thus facilitates stool passage (Krogh et al., 2017). These treatments are useful for patients with mild-to-moderate constipation, and the main side effects are diarrhea and abdominal distention.

\section{Lactulose}

As an osmotic laxative, lactulose has osmotic activity and can attract water to the colon cavity (Jouët et al., 2008). Since it is harmless to the human body and can effectively regulate the physiological rhythm of the colon, it is widely used to treat constipation in the elderly, pregnant women, and children. Adverse reactions are limited to the gastrointestinal system, with bloating and abdominal pain being the most common.

\section{Polyethylene Glycol}

Polyethylene glycol is a non-absorbable macromolecule belonging to the group of osmotic laxatives. Its mechanism of action is physical; it acts through local infiltration, retaining water in the colon cavity, thus softening feces, increasing fecal volume, and leading to unobstructed defecation. Polyethylene glycol can improve constipation-related symptoms (such as stool frequency and stool consistency) (Chassagne et al., 2017). Clinical studies have found that low-dose polyethylene glycol is significantly better than lactulose in improving constipation symptoms, with fewer adverse reactions (Attar et al., 1999). Polyethylene glycol can be used for the symptomatic treatment of constipation in children aged 6 months and older and in adults. 


\section{Poorly Absorbed Salts}

Salt laxative $\mathrm{MgSO}_{4}$ can increase the intestinal osmotic pressure, prevent the absorption of water in the colon, increase the intestinal contents, and stimulate intestinal peristalsis, resulting in rapid and severe catharsis. The increased intracellular $\mathrm{Mg}^{2+}$ concentration activates adenylate cyclase (AC), which leads to an increase in cAMP. The increased cAMP concentration subsequently leads to the activation of PKA, which promotes CREB phosphorylation and AQP3 gene transcription (Ikarashi et al., 2011b). Excessive use of salt laxatives may induce electrolyte disorders and are therefore, not suitable for the elderly and patients with decreased kidney-function.

\section{Stimulant Laxatives}

If the patient does not respond to osmotic laxatives, stimulant laxatives are recommended. Stimulant laxatives stimulate the intestinal mucosa and nerve plexus to secrete water and electrolytes, resulting in peristaltic contraction, thereby accelerating colonic transport. Stimulant laxatives are effective, and their side effects are known. Chronic use of stimulant laxatives does not seem to cause tolerance or rebound constipation. However, common side effects include diarrhea and abdominal pain (Wald, 2003).

\section{Bisacodyl}

Bisacodyl stimulates the secretion and motility of the small intestine and colon via the following mechanisms: increased secretion of TNF- $\alpha$ and prostaglandin $\mathrm{E}_{2}\left(\mathrm{PGE}_{2}\right)$ in the colon following the oral administration of bisacodyl. TNF- $\alpha$ and $\mathrm{PGE}_{2}$, as paracrine factors, act on the colonic mucosal epithelial cells resulting in an immediate reduction in AQP3 expression, thus exerting their laxative effects (Ikarashi et al., 2011a). In a 4-weeks trial, oral bisacodyl was reported to be safe and well-tolerated (Kamm et al., 2011). However, bisacodyl is associated with abdominal cramps and diarrhea.

\section{Secretagogues}

Secretagogues are second-line drugs, the effects of which are similar to those of osmotic laxatives. Secretagogues act directly on intestinal epithelial cells, increasing fluid secretion into the intestinal cavity, thereby changing the consistency of stools and reducing the transit time in the colon (Luthra et al., 2019). However, these drugs are associated with side effects such as diarrhea when used clinically.

\section{Lubiprostone}

Lubiprostone is a prostaglandin $\mathrm{E}_{1}$ derivative, which can activate the intestinal chloride channel type 2 on the apical surface of small intestinal enterocytes, thereby reducing epithelial permeability and promoting intestinal fluid secretion. Lubiprostone selectively activates type $2 \mathrm{Cl}^{-}$channels in the parietal membrane of the gastrointestinal epithelium, resulting in the excretion of $\mathrm{Cl}^{-}$ions through the periapical membrane. Additionally, sodium and water enter the intestinal cavity passively, increasing the secretion of fluid in the intestinal cavity (Gonzalez-Martinez et al., 2014). Lubiprostone can significantly increase stool frequency, improve stool consistency, and reduce straining, which makes it effective for the treatment of constipation (Nishii et al., 2020). The results of a meta-analysis showed that adverse reactions such as nausea, vomiting, and diarrhea were common (incidence rate, 2.4-75\%) (Li et al., 2016). This may be related to the rapid flow of fluid into the small intestine after taking the medicine.

\section{Guanylate Cyclase-C (GC-C) Receptor Agonists}

Plecanatide and Linaclotide are GC-C receptor agonists that target GC-C receptors on the lumen of the intestinal epithelium, resulting in increased intestinal fluid secretion (Shah et al., 2018). By activating colonic epithelial GC-C receptors, the synthesis of intracellular and extracellular cGMP is increased (Busby et al., 2010). CFTR is activated indirectly by cGMP and induces epithelial cells to secrete $\mathrm{Cl}^{-}$and $\mathrm{HCO}_{3}{ }^{-}$, inhibits $\mathrm{Na}^{+}$absorption, and thus promotes intestinal water secretion (Layer and Stanghellini, 2014). Intestinal dilatation caused by increased intestinal fluid can promote intestinal movement, and therefore treat constipation. The reported efficacy of plecanatide and linaclotide is similar, and the most common side effect is diarrhea (Bassotti et al., 2018; Bassotti et al., 2019). Furthermore, increased cGMP can regulate abdominal pain (Silos-Santiago et al., 2013), thus, both drugs can relieve abdominal pain (Castro et al., 2013; Brenner et al., 2018).

\section{Serotonergic Agents}

The use of osmotic and stimulant laxatives, either alone or in combination, may be considered in first-line drug therapy. Second-line agents, such as prucalopride are indicated in patients with an inadequate response or poor tolerance to a first-line drug. Studies have reported that exploiting epithelial targets with nonabsorbable serotonergic agents could provide safe and effective therapies. Serotonin agonists stimulate intestinal secretion and motility by activating 5-HT receptors in the gastrointestinal nervous system. Unlike other older nonselective $5-\mathrm{HT}_{4}$ receptor agonists (e.g., cisapride and tegaserod), prucalopride is effective for the treatment of chronic constipation and has demonstrated an excellent safety profile (Hayat et al., 2017).

\section{Prucalopride}

Prucalopride is a high-affinity $5-\mathrm{HT}_{4}$ receptor agonist with colonic prokinetic activity (Vijayvargiya and Camilleri, 2019). Prucalopride functions by activating $5-\mathrm{HT}_{4}$ receptors in myenteric plexus neurons and stimulates HAPCs to increase colonic motility (Miner et al., 2016). This significantly increases intestinal muscle contraction, as well as stool frequency and consistency in patients with chronic constipation. Some studies have also found that prucalopride can increase the expression of c-kit mRNA in colonic tissue of rats with constipation, and then improve the function of ICCs, so as to promote colonic motility. It is effective at improving stool frequency, stool consistency and straining. The most common side effects include diarrhea, headache, nausea, and abdominal pain (Daniali et al., 2019). Multicenter, double-blind, randomized, placebo-controlled trials have demonstrated that 
prucalopride is superior to placebo in the short to medium term and can improve constipation in both men and women across a broad spectrum of ages and ethnicities (Camilleri et al., 2016). Nevertheless, this drug is considerably more expensive than conventional therapy. With knowledge that $5-\mathrm{HT}_{3}$ receptors can participate in the activation of propulsive motility and secretory responses in the gut, $5-\mathrm{HT}_{3}$ agonists have been developed and tested for the treatment of constipation (Mawe and Hoffman, 2013).

\section{Ileal Bile Acid Transporter Inhibitor}

Bile acid can activate the secretory activity of colonic epithelial cells (Mekjian et al., 1971). Therefore, up-regulation of the colonic bile acid concentration can be used to treat patients with constipation. Bile acid, a natural laxative in the human body, has garnered attention for the treatment of chronic constipation because of its ability to promote colonic epithelial secretion (Keely et al., 2007). However, its efficacy and safety need to be further confirmed in large scale studies.

\section{Elobixibat}

Bile acid acts as a physiological laxative by activating AC, increasing mucosal permeability, and inhibiting apical $\mathrm{Cl}^{-} /$ $\mathrm{OH}^{-}$exchange to alter the transport of electrolytes and water in the lumen. Elobixibat can block the enterohepatic circulation of bile acid, up-regulate the synthesis of bile acid reaching the colon, and stimulate the secretion of fluid and electrolytes, thereby increasing fecal water content and gut motility (Mekjian et al., 1971). Increased gut motility facilitates stool passage. Few adverse reactions have been associated with this drug and they include abdominal pain and diarrhea. Abdominal pain with elobixibat may be related to its ability to induce dilatation and contraction (Taniguchi et al., 2018).

\section{Motilin Receptor Agonists}

As a motilin receptor agonist, mitemcinal (GM-611) can stimulate and promote peristalsis of the gastrointestinal tract by acting on the motilin receptor (Sudo et al., 2007). This effect has been observed in animal models; however, due to a lack of clinical outcome data, the clinical significance of these studies has not been clearly demonstrated. Therefore, further clinical trials are required to confirm the efficacy and safety of mitemcinal in this population (Mozaffari et al., 2014).

\section{Probiotics}

Probiotic consumption can regulate the intestinal microbiota of patients with constipation, which in turn, can improve gut motility. Some studies have shown that probiotics can be helpful for treating patients with constipation (improved stool frequency and stool consistency) with very few side effects (Ohkusa et al., 2019; Zhang et al., 2020). These studies have mainly involved the bacteroides, bifidobacterial, and lactobacilli. Recently, the positive impacts of SCFAs on gut motility and constipation were established (Chu et al., 2019). Nevertheless, since the effects of probiotics may be strain-specific and the exact mechanism of action remains unknown, more studies and randomized controlled trials are needed to confirm the effects of probiotics in patients with constipation (Dimidi et al., 2020).

\section{Traditional Chinese Medicine}

Traditional Chinese Medicine (TCM) has a role in promoting gastrointestinal motility and has been used to treat constipation for more than 1,000 years in China. In recent years, there have been many reports about TCM in the treatment of constipation and the improvement of gastrointestinal function (Cirillo and Capasso, 2015). Therefore, TCM has garnered increasing attention as a promising alternative treatment for constipation. However, few studies have investigated its therapeutic mechanisms. Thus, the long-term efficacy and side-effect profiles of these medicines in modern medicine need to be determined. Further studies are needed to determine the exact mechanism for the observed recovery of intestinal function. Importantly, the composition of TCM is complex.

Senna and rhubarb are anthraquinone laxatives used widely in the treatment of intestinal constipation. Sennoside A exerts a laxative effect through its main bioactive component. Rheinanthrone, the active metabolite of sennoside $A$, can increase the production of $\mathrm{PGE}_{2}$ (Kon et al., 2014), thus participating in the regulation of intestinal peristaltic reflex. Emodin in rhubarb may also regulate water transport and absorption via the cAMP-dependent PKA/p-CREB signal pathway to change AQP3 (Zheng et al., 2014). Owing to its toxicity to the kidney and liver, we suggest that special attention should be paid to patients with kidney and liver diseases when using Senna drugs for a long period (Cao et al., 2018).

Total glucosides of paeony (TGP) are extracted from the root of Paeonia Lactiflora Pall. Studies have shown that TGP can improve the function of ICCs, block inhibitory neurotransmitters such as NO, NOS, and VIP, and increase the fecal volume and water content, as well as intestinal transit rate (Zhu et al., 2016).

\section{CONCLUSION AND PROSPECT}

As a common disease that seriously impacts the quality of life and mental health of patients, chronic constipation has attracted widespread attention. In general, impaired gut motility, fluid secretion/absorption, and electrolyte transport can result in decreased intestinal transit, reduced fluid secretion, and increased fluid reabsorption, which will eventually lead to chronic constipation. Further studies on the abnormal changes of the ENS, ANS, CNS, endocrine signaling, and microbiota would aid our understanding of constipation from the perspective of gut motility. Intestinal fluid and electrolyte transport are also strongly correlated with chronic constipation. As a subject for future research, ion channels and AQPs play critical roles in the transport of fluid. At present, studies on ion transport and AQPs in constipation are limited, and many complex mechanisms have not been clarified. Further experiments are warranted to demonstrate this mechanism.

With extended symptom duration, severity, and frustration, the occurrence of additional symptoms will also increase. 
Therefore, patients with chronic constipation usually require active treatment. The choice of therapeutic drugs should focus on the effectiveness of relieving the symptoms of constipation, the improvement of the intestinal environment, and the effectiveness and safety of long-term use. Preferentially, fiber/osmotic/ stimulant laxatives should be considered. If these measures fail, prescription laxatives with different mechanisms of action may be used. Modifying the gut luminal environment through gut motility, fluid, and electrolytes will affect transit and secretion in the gut, thereby benefiting patients with chronic constipation. Intestinal fluid transport mediated by ion channels and AQPs is the key mechanism through which many laxatives exert their effects. An in-depth understanding of ion channels and water channels in constipation will provide a scientific basis for the development of synergistic and/or antagonistic drugs targeting specific channels. Nevertheless, further studies are still required to resolve the problem. Recently, the action of probiotics on gut motility was shown to be beneficial for constipation. However, the positive effects of probiotics depend on the specific probiotics used and the level applied. Therefore, the use of probiotics in the treatment of chronic constipation is promising and further studies are required. We hope that a better understanding of the pathogenesis of constipation and the mechanism of drug

\section{REFERENCES}

Ahmed, M., and Ahmed, S. (2019). Functional, Diagnostic and Therapeutic Aspects of Gastrointestinal Hormones. Gastroenterol. Res. 12 (5), 233-244. doi:10.14740/gr1219

Attar, A., Lémann, M., Ferguson, A., Halphen, M., Boutron, M.-C., Flourié, B., et al. (1999). Comparison of a Low Dose Polyethylene Glycol Electrolyte Solution with Lactulose for Treatment of Chronic Constipation. Gut 44 (2), 226-230. doi:10.1136/gut.44.2.226

Aubé, A.-C., Cabarrocas, J., Bauer, J., Philippe, D., Aubert, P., Doulay, F., et al. (2006). Changes in Enteric Neurone Phenotype and Intestinal Functions in a Transgenic Mouse Model of Enteric Glia Disruption. Gut 55 (5), 630-637. doi:10.1136/gut.2005.067595

Avetisyan, M., Schill, E. M., and Heuckeroth, R. O. (2015). Building a Second Brain in the Bowel. J. Clin. Invest. 125 (3), 899-907. doi:10.1172/JCI76307

Aviello, G., Romano, B., and Izzo, A. A. (2008). Cannabinoids and Gastrointestinal Motility: Animal and Human Studies. Eur. Rev. Med. Pharmacol. Sci. Suppl 1, 81-93.

Barrett, K. E. (2017). Endogenous and Exogenous Control of Gastrointestinal Epithelial Function: Building on the Legacy of Bayliss and Starling. J. Physiol. 595 (2), 423-432. doi:10.1113/JP272227

Bassotti, G., Chistolini, F., Marinozzi, G., and Morelli, A. (2003). Abnormal Colonic Propagated Activity in Patients with Slow Transit Constipation and Constipation-Predominant Irritable Bowel Syndrome. Digestion 68 (4), 178-183. doi:10.1159/000075554

Bassotti, G., Usai-Satta, P., and Bellini, M. (2018). Linaclotide for the Treatment of Chronic Constipation. Expert Opin. Pharmacother. 19 (11), 1261-1266. doi:10.1080/14656566.2018.1494728

Bassotti, G., Usai Satta, P., and Bellini, M. (2019). Plecanatide for the Treatment of Chronic Idiopathic Constipation in Adult Patients. Expert Rev. Clin. Pharmacol. 12 (11), 1019-1026. doi:10.1080/ 17512433.2019.1670057

Beck, K., Voussen, B., Reigl, A., Vincent, A. D., Parsons, S. P., Huizinga, J. D., et al. (2019). Cell-specific Effects of Nitric Oxide on the Efficiency and Frequency of Long Distance Contractions in Murine colon. Neurogastroenterol. Motil. 31 (6), e13589. doi:10.1111/nmo.13589 action may create new targets for the treatment of diseases that remain a major scourge worldwide.

\section{AUTHOR CONTRIBUTIONS}

Y-YC and Y-PT conceived and designed the review. QZ searched the literature and drafted the manuscript. D-QX and S-JY additions and revisions in manuscript. JY and L-MX examined the literature and made the figures. R-JF edited the manuscript. Y-YC and Y-PT made a critical revision of the review. All authors approved the final version of the manuscript.

\section{FUNDING}

This work was supported by the National Natural Science Foundation of China (81974525), Cultivation Plan of Young Scientific and Technological Stars in Shaanxi Province (2021), The Youth Innovation Team of Shaanxi Universities (2020), Natural Science Foundation of Shaanxi Provincial Department of Education (17jk0205), and Subject Innovation Team of Shaanxi University of Chinese Medicine (2019-YL10).

Bharucha, A. E., and Lacy, B. E. (2020). Mechanisms, Evaluation, and Management of Chronic Constipation. Gastroenterology 158 (5), 1232-1249.e3. doi:10.1053/ j.gastro.2019.12.034

Bharucha, A. E., Dorn, S. D., Lembo, A., and Pressman, A. (2013). American Gastroenterological Association Medical Position Statement on Constipation. Gastroenterology 144 (1), 211-217. doi:10.1053/j.gastro.2012.10.029

Black, C. J., and Ford, A. C. (2018). Chronic Idiopathic Constipation in Adults: Epidemiology, Pathophysiology, Diagnosis and Clinical Management. Med. J. Aust. 209 (2), 86-91. doi:10.5694/mja18.00241

Bonaz, B., Bazin, T., and Pellissier, S. (2018). The Vagus Nerve at the Interface of the Microbiota-Gut-Brain Axis. Front. Neurosci. 12, 49. doi:10.3389/fnins.2018.00049

Bossola, M., Di Stasio, E., Sanguinetti, M., Posteraro, B., Antocicco, M., Pepe, G., et al. (2016). Serum Endotoxin Activity Measured with Endotoxin Activity Assay Is Associated with Serum Interleukin-6 Levels in Patients on Chronic Hemodialysis. Blood Purif. 42 (4), 294-300. doi:10.1159/000449096

Brenner, D. M., Fogel, R., Dorn, S. D., Krause, R., Eng, P., Kirshoff, R., et al. (2018). Efficacy, Safety, and Tolerability of Plecanatide in Patients with Irritable Bowel Syndrome with Constipation: Results of Two Phase 3 Randomized Clinical Trials. Am. J. Gastroenterol. 113 (5), 735-745. doi:10.1038/s41395-018-0026-7

Busby, R. W., Bryant, A. P., Bartolini, W. P., Cordero, E. A., Hannig, G., Kessler, M. M., et al. (2010). Linaclotide, through Activation of Guanylate Cyclase C, Acts Locally in the Gastrointestinal Tract to Elicit Enhanced Intestinal Secretion and Transit. Eur. J. Pharmacol. 649, 328-335. doi:10.1016/j.ejphar.2010.09.019

Cai, Q., Buono, J. L., Spalding, W. M., Sarocco, P., Tan, H., Stephenson, J. J., et al. (2014). Healthcare Costs Among Patients with Chronic Constipation: a Retrospective Claims Analysis in a Commercially Insured Population. J. Med. Econ. 17 (2), 148-158. doi:10.3111/13696998.2013.860375

Camilleri, M., Piessevaux, H., Yiannakou, Y., Tack, J., Kerstens, R., Quigley, E. M. M., et al. (2016). Efficacy and Safety of Prucalopride in Chronic Constipation: An Integrated Analysis of Six Randomized, Controlled Clinical Trials. Dig. Dis. Sci. 61 (8), 2357-2372. doi:10.1007/s10620-016-4147-9

Camilleri, M., Ford, A. C., Mawe, G. M., Dinning, P. G., Rao, S. S., Chey, W. D., et al. (2017). Chronic Constipation. Nat. Rev. Dis. Primers. 3, 17095. doi:10.1038/nrdp10.1038/nrdp.2017.95

Cao, Y., He, Y., Wei, C., Li, J., Qu, L., Zhang, H., et al. (2018). Aquaporins Alteration Profiles Revealed Different Actions of Senna, Sennosides, and Sennoside A in Diarrhea-Rats. Ijms 19 (10), 3210. doi:10.3390/ijms19103210 
Castro, J., Harrington, A. M., Hughes, P. A., Martin, C. M., Ge, P., Shea, C. M., et al. (2013). Linaclotide Inhibits Colonic Nociceptors and Relieves Abdominal Pain via Guanylate Cyclase-C and Extracellular Cyclic Guanosine $3^{\prime}, 5^{\prime}$ Monophosphate. Gastroenterology 145 (6), 1334-1346.e1-11. doi:10.1053/ j.gastro.2013.08.017

Ceccotti, C., Giaroni, C., Bistoletti, M., Viola, M., Crema, F., and Terova, G. (2018). Neurochemical Characterization of Myenteric Neurons in the Juvenile Gilthead Sea Bream (Sparus aurata) Intestine. PLoS One 13 (8), e0201760. doi:10.1371/ journal.pone.0201760

Chandrasekharan, B., Nezami, B. G., and Srinivasan, S. (2013). Emerging Neuropeptide Targets in Inflammation: NPY and VIP. Am. J. Physiol. Gastrointest. Liver Physiol. 304 (11), G949-G957. doi:10.1152/ajpgi.00493.2012

Chassagne, P., Ducrotte, P., Garnier, P., and Mathiex-Fortunet, H. (2017). Tolerance and Long-Term Efficacy of Polyethylene Glycol 4000 (Forlax) Compared to Lactulose in Elderly Patients with Chronic Constipation. J. Nutr. Health Aging 21 (4), 429-439. doi:10.1007/s12603-016-0762-6

Chu, J. R., Kang, S.-Y., Kim, S.-E., Lee, S.-J., Lee, Y.-C., and Sung, M.-K. (2019). Prebiotic UG1601 Mitigates Constipation-Related Events in Association with Gut Microbiota: A Randomized Placebo-Controlled Intervention Study. Wjg 25 (40), 6129-6144. doi:10.3748/wjg.v25.i40.6129

Cirillo, C., and Capasso, R. (2015). Constipation and Botanical Medicines: An Overview. Phytother. Res. 29 (10), 1488-1493. doi:10.1002/ptr.5410

Cohen, M., Cazals-Hatem, D., Duboc, H., Sabate, J.-M., Msika, S., Slove, A. L., et al. (2017). Evaluation of Interstitial Cells of Cajal in Patients with Severe Colonic Inertia Requiring Surgery: a Clinical-Pathological Study. Colorectal Dis. 19 (5), 462-467. doi:10.1111/codi.13511

Daniali, M., Nikfar, S., and Abdollahi, M. (2019). An Overview of the Efficacy and Safety of Prucalopride for the Treatment of Chronic Idiopathic Constipation. Expert Opin. Pharmacother. 20 (17), 2073-2080. doi:10.1080/ 14656566.2019 .1668927

Dawson, D. C. (1991). Ion Channels and Colonic Salt Transport. Annu. Rev. Physiol. 53 (1), 321-340. doi:10.1146/annurev.ph.53.030191.001541

De, G. R., Guerrini, S., Barbara, G., Cremon, C., Stanghellini, V., and Corinaldesi, R. (2004). New Insights into Human Enteric Neuropathies. Neurogastroenterol Motil. 16 (Suppl. 1), 143-147. doi:10.1111/j.1743-3150.2004.00491.x

Dimidi, E., Christodoulides, S., Scott, S. M., and Whelan, K. (2017). Mechanisms of Action of Probiotics and the Gastrointestinal Microbiota on Gut Motility and Constipation. Adv. Nutr. 8 (3), 484-494. doi:10.3945/an.116.014407

Dimidi, E., Mark Scott, S., and Whelan, K. (2020). Probiotics and Constipation: Mechanisms of Action, Evidence for Effectiveness and Utilisation by Patients and Healthcare Professionals - ERRATUM. Proc. Nutr. Soc. 79 (1), 170. doi:10.1017/S0029665119001058

Dinning, P. G., and Di Lorenzo, C. (2011). Colonic Dysmotility in Constipation. Best Pract. Res. Clin. Gastroenterol. 25 (1), 89-101. doi:10.1016/ j.bpg.2010.12.006

Esteban-Zubero, E., López-Pingarrón, L., Alatorre-Jiménez, M. A., Ochoa-Moneo, P., Buisac-Ramón, C., Rivas-Jiménez, M., et al. (2017). Melatonin's Role as a Co-adjuvant Treatment in Colonic Diseases: A Review. Life Sci. 170, 72-81. doi:10.1016/j.lfs.2016.11.031

Fukumoto, S., Tatewaki, M., Yamada, T., Fujimiya, M., Mantyh, C., Voss, M., et al. (2003). Short-chain Fatty Acids Stimulate Colonic Transit via Intraluminal 5HT Release in Rats. Am. J. Physiol. Regul. Integr. Comp. Physiol. 284 (5), R1269-R1276. doi:10.1152/ajpregu.00442.2002

Furness, J. B. (2000). Types of Neurons in the Enteric Nervous System. J. Auton. Nervous Syst. 81, 87-96. doi:10.1016/s0165-1838(00)00127-2

Gershon, M. D., and Tack, J. (2007). The Serotonin Signaling System: from Basic Understanding to Drug Development for Functional GI Disorders. Gastroenterology 132 (1), 397-414. doi:10.1053/j.gastro.2006.11.002

Gershon, M. D. (2012). Serotonin Is a Sword and a Shield of the Bowel: Serotonin Plays Offense and Defense. Trans. Am. Clin. Climatol. Assoc. 123, 268-280.

Gonzalez-Martinez, M. A., Ortiz-Olvera, N. X., and Mendez-Navarro, J. (2014). Novel Pharmacological Therapies for Management of Chronic Constipation. J. Clin. Gastroenterol. 48 (1), 21-28. doi:10.1097/01.mcg.0000436440.05887.02

Grubišić, V., and Gulbransen, B. D. (2017). Enteric Glial Activity Regulates Secretomotor Function in the Mouse colon but Does Not Acutely Affect Gut Permeability. J. Physiol. 595 (11), 3409-3424. doi:10.1113/JP273975

Guerin, A., Carson, R. T., Lewis, B., Yin, D., Kaminsky, M., and Wu, E. (2014). The Economic burden of Treatment Failure Amongst Patients with Irritable Bowel
Syndrome with Constipation or Chronic Constipation: a Retrospective Analysis of a Medicaid Population. J. Med. Econ. 17 (8), 577-586. doi:10.3111/ 13696998.2014 .919926

Haggie, P. M., Cil, O., Lee, S., Tan, J.-A., Rivera, A. A., Phuan, P.-W., et al. (2018). SLC26A3 Inhibitor Identified in Small Molecule Screen Blocks Colonic Fluid Absorption and Reduces Constipation. JCI. Insight 3 (14), e121370. doi:10.1172/jci.insight.121370

Hamabata, T., Liu, C., and Takeda, Y. (2002). Positive and Negative Regulation of Water Channel Aquaporins in Human Small Intestine by Cholera Toxin. Microb. Pathog. 32 (6), 273-277. doi:10.1006/mpat.2002.0502

Hayat, U., Dugum, M., and Garg, S. (2017). Chronic Constipation: Update on Management. Ccjm 84 (5), 397-408. doi:10.3949/ccjm.84a.15141

Heinemann, Á., Shahbazian, A., Barthó, L., and Holzer, P. (1999). Different Receptors Mediating the Inhibitory Action of Exogenous ATP and Endogenously Released Purines on guinea-pig Intestinal Peristalsis. $\mathrm{Br}$. J. Pharmacol. 128 (2), 313-320. doi:10.1038/sj.bjp.0702808

Ikarashi, N., Baba, K., Ushiki, T., Kon, R., Mimura, A., Toda, T., et al. (2011a). The Laxative Effect of Bisacodyl Is Attributable to Decreased Aquaporin-3 Expression in the colon Induced by Increased PGE2 Secretion from Macrophages. Am. J. Physiol. Gastrointest. Liver Physiol. 301 (5), G887-G895. doi:10.1152/ajpgi.00286.2011

Ikarashi, N., Mochiduki, T., Takasaki, A., Ushiki, T., Baba, K., Ishii, M., et al. (2011b). A Mechanism by Which the Osmotic Laxative Magnesium Sulphate Increases the Intestinal Aquaporin 3 Expression in HT-29 Cells. Life Sci. 88 (34), 194-200. doi:10.1016/j.lfs.2010.11.013

Ikeda, M., and Matsuzaki, T. (2015). Regulation of Aquaporins by Vasopressin in the Kidney. Vitam. Horm. 98, 307-337. doi:10.1016/bs.vh.2014.12.008

Itoh, A., Tsujikawa, T., Fujiyama, Y., and Bamba, T. (2003). Enhancement of Aquaporin-3 by Vasoactive Intestinal Polypeptide in a Human Colonic Epithelial Cell Line. J. Gastroenterol. Hepatol. 18 (2), 203-210. doi:10.1046/ j.1440-1746.2003.02949.x

Jakab, R. L., Collaco, A. M., and Ameen, N. A. (2013). Characterization of CFTR High Expresser Cells in the Intestine. Am. J. Physiol. Gastrointest. Liver Physiol. 305 (6), G453-G465. doi:10.1152/ajpgi.00094.2013

John, E. S., and Chokhavatia, S. (2017). Targeting Small Bowel Receptors to Treat Constipation and Diarrhea. Curr. Gastroenterol. Rep. 19 (7), 31. doi:10.1007/ s11894-017-0573-x

Jouët, P., Sabate, J.-M., Flourie, B., Cuillerier, E., Gambini, D., Lemann, M., et al. (2008). Effects of Therapeutic Doses of Lactulose vs. Polyethylene Glycol on Isotopic Colonic Transit. Aliment. Pharmacol. Ther. 27 (10), 988-993. doi:10.1111/j.1365-2036.2008.03654.x

Jun, J. Y., Choi, S., Yeum, C. H., Chang, I. Y., You, H. J., Park, C. K., et al. (2004). Substance P Induces Inward Current and Regulates Pacemaker Currents through Tachykinin NK1 Receptor in Cultured Interstitial Cells of Cajal of Murine Small Intestine. Eur. J. Pharmacol. 495 (1), 35-42. doi:10.1016/ j.ejphar.2004.05.022

Kagnoff, M. F. (2014). The Intestinal Epithelium Is an Integral Component of a Communications Network. J. Clin. Invest. 124 (7), 2841-2843. doi:10.1172/ JCI75225

Kamm, M. A., Mueller-Lissner, S., Wald, A., Richter, E., Swallow, R., and Gessner, U. (2011). Oral Bisacodyl Is Effective and Well-Tolerated in Patients with Chronic Constipation. Clin. Gastroenterol. Hepatol. 9 (7), 577-583. doi:10.1016/j.cgh.2011.03.026

Kato, A., and Romero, M. F. (2011). Regulation of Electroneutral NaCl Absorption by the Small Intestine. Annu. Rev. Physiol. 73 (1), 261-281. doi:10.1146/ annurev-physiol-012110-142244

Keely, S. J., Scharl, M. M., Bertelsen, L. S., Hagey, L. R., Barrett, K. E., and Hofmann, A. F. (2007). Bile Acid-Induced Secretion in Polarized Monolayers of T84 Colonic Epithelial Cells: Structure-Activity Relationships. Am. J. Physiol. Gastrointest. Liver Physiol. 292 (1), G290-G297. doi:10.1152/ajpgi.00076.2006

Klein, S., Seidler, B., Kettenberger, A., Sibaev, A., Rohn, M., Feil, R., et al. (2013). Interstitial Cells of Cajal Integrate Excitatory and Inhibitory Neurotransmission with Intestinal Slow-Wave Activity. Nat. Commun. 4, 1630. doi:10.1038/ ncomms 2626

Komuro, T. (2006). Structure and Organization of Interstitial Cells of Cajal in the Gastrointestinal Tract. J. Physiol. 576, 653-658. doi:10.1113/ jphysiol.2006.116624 
Kon, R., Ikarashi, N., Nagoya, C., Takayama, T., Kusunoki, Y., Ishii, M., et al. (2014). Rheinanthrone, a Metabolite of Sennoside A, Triggers Macrophage Activation to Decrease Aquaporin-3 Expression in the colon, Causing the Laxative Effect of Rhubarb Extract. J. Ethnopharmacol. 152 (1), 190-200. doi:10.1016/j.jep.2013.12.055

Krogh, K., Chiarioni, G., and Whitehead, W. (2017). Management of Chronic Constipation in Adults. United Eur. Gastroenterol. J. 5 (4), 465-472. doi:10.1177/2050640616663439

Kunzelmann, K., Hübner, M., Schreiber, R., Levy-Holzman, R., Garty, H., Bleich, M., et al. (2001). Cloning and Function of the Rat Colonic Epithelial K + Channel K V LQT1. J. Membr. Biol. 179 (2), 155-164. doi:10.1007/ s002320010045

Kunzelmann, K., Centeio, R., Wanitchakool, P., Cabrita, I., Benedetto, R., Saha, T., et al. (2019). Control of Ion Transport by Tmem16a Expressed in Murine Intestine. Front. Physiol. 10, 1262. doi:10.3389/fphys.2019.01262

Lacy, B. E., Mearin, F., Chang, L., Chey, W. D., Lembo, A. J., Simren, M., et al. (2016). Bowel Disorders. Gastroenterology 150, 1393-1407. doi:10.1053/ j.gastro.2016.02.031

Laforenza, U., Gastaldi, G., Grazioli, M., Cova, E., Tritto, S., Faelli, A., et al. (2005). Expression and Immunolocalization of Aquaporin-7 in Rat Gastrointestinal Tract. Biol. Cel 97 (8), 605-613. doi:10.1042/BC20040090

Layer, P., and Stanghellini, V. (2014). Review Article: Linaclotide for the Management of Irritable Bowel Syndrome with Constipation. Aliment. Pharmacol. Ther. 39 (4), 371-384. doi:10.1111/apt.12604

Li, y.-y., Li, y.-n., Ni, j.-b., Chen, c.-j., Lv, S., Chai, s.-y., et al. (2010). Involvement of Cannabinoid-1 and Cannabinoid-2 Receptors in Septic Ileus. Neurogastroenterol Motil. 22 (3), 350-e88. doi:10.1111/j.13652982.2009.01419.x

Li, F., Fu, T., Tong, W.-D., Liu, B.-H., Li, C.-X., Gao, Y., et al. (2016). Lubiprostone Is Effective in the Treatment of Chronic Idiopathic Constipation and Irritable Bowel Syndrome. Mayo Clinic Proc. 91 (4), 456-468. doi:10.1016/ j.mayocp.2016.01.015

Lin, A. Y., Du, P., Dinning, P. G., Arkwright, J. W., Kamp, J. P., Cheng, L. K., et al. (2017). High-resolution Anatomic Correlation of Cyclic Motor Patterns in the Human colon: Evidence of a Rectosigmoid Brake. Am. J. Physiol. Gastrointest. Liver Physiol. 312 (5), G508-G515. doi:10.1152/ajpgi.00021.2017

Luthra, P., Camilleri, M., Burr, N. E., Quigley, E. M. M., Black, C. J., and Ford, A. C. (2019). Efficacy of Drugs in Chronic Idiopathic Constipation: a Systematic Review and Network Meta-Analysis. Lancet Gastroenterol. Hepatol. 4 (11), 831-844. doi:10.1016/S2468-1253(19)30246-8

Malsure, S., Wang, Q., Charles, R.-P., Sergi, C., Perrier, R., Christensen, B. M., et al. (2014). Colon-specific Deletion of Epithelial Sodium Channel Causes Sodium Loss and Aldosterone Resistance. Jasn 25 (7), 1453-1464. doi:10.1681/ ASN.2013090936

Martinez-Cutillas, M., Gil, V., Mañé, N., Clavé, P., Gallego, D., Martin, M. T., et al. (2015). Potential Role of the Gaseous Mediator Hydrogen Sulphide (H2S) in Inhibition of Human Colonic Contractility. Pharmacol. Res. 93, 52-63. doi:10.1016/j.phrs.2015.01.002

Mawe, G. M., and Hoffman, J. M. (2013). Serotonin Signalling in the GutFunctions, Dysfunctions and Therapeutic Targets. Nat. Rev. Gastroenterol. Hepatol. 10 (8), 473-486. doi:10.1038/nrgastro.2013.105

Mayer, E. A., and Tillisch, K. (2011). The Brain-Gut axis in Abdominal Pain Syndromes. Annu. Rev. Med. 62, 381-396. doi:10.1146/annurev-med-012309103958

Mayer, E. A., Savidge, T., and Shulman, R. J. (2014). Brain-gut Microbiome Interactions and Functional Bowel Disorders. Gastroenterology 146 (6), 1500-1512. doi:10.1053/j.gastro.2014.02.037

Mekjian, H. S., Phillips, S. F., and Hofmann, A. F. (1971). Colonic Secretion of Water and Electrolytes Induced by Bile Acids: Perfusion Studies in Man. J. Clin. Invest. 50 (8), 1569-1577. doi:10.1172/JCI106644

Miner, P. B., Camilleri, M., Burton, D., Achenbach, H., Wan, H., Dragone, J., et al. (2016). Prucalopride Induces High-amplitude Propagating Contractions in the colon of Patients with Chronic Constipation: a Randomized Study. Neurogastroenterol. Motil. 28 (9), 1341-1348. doi:10.1111/nmo.12832

Mourad, F. H., and Nassar, C. F. (2000). Effect of Vasoactive Intestinal Polypeptide (VIP) Antagonism on Rat Jejunal Fluid and Electrolyte Secretion Induced by Cholera and Escherichia coli Enterotoxins. Gut 47 (3), 382-386. doi:10.1136/ gut.47.3.382
Mozaffari, S., Didari, T., Nikfar, S., and Abdollahi, M. (2014). Phase II Drugs under Clinical Investigation for the Treatment of Chronic Constipation. Expert Opin. Investig. Drugs 23 (11), 1485-1497. doi:10.1517/13543784.2014.932770

Nishii, N., Oshima, T., Li, M., Eda, H., Nakamura, K., Tamura, A., et al. (2020). Lubiprostone Induces Claudin-1 and Protects Intestinal Barrier Function. Pharmacology 105, 102-108. doi:10.1159/000503054

Ohkusa, T., Koido, S., Nishikawa, Y., and Sato, N. (2019). Gut Microbiota and Chronic Constipation: A Review and Update. Front. Med. 6, 19. doi:10.3389/ fmed.2019.00019

Parajuli, S. P., Choi, S., Lee, J., Kim, Y. D., Park, C. G., Kim, M. Y., et al. (2010). The Inhibitory Effects of Hydrogen Sulfide on Pacemaker Activity of Interstitial Cells of Cajal from Mouse Small Intestine. Korean J. Physiol. Pharmacol. 14 (2), 83-89. doi:10.4196/kjpp.2010.14.2.83

Patel-Chamberlin, M., Varasteh Kia, M., Xu, J., Barone, S., Zahedi, K., and Soleimani, M. (2016). The Role of Epithelial Sodium Channel ENaC and the Apical Cl-/HCO3- Exchanger Pendrin in Compensatory Salt Reabsorption in the Setting of $\mathrm{Na}-\mathrm{Cl}$ Cotransporter (NCC) Inactivation. PLoS One 11 (3), e0150918. doi:10.1371/journal.pone.0150918

Peery, A. F., Crockett, S. D., Murphy, C. C., Lund, J. L., Dellon, E. S., Williams, J. L., et al. (2019). Burden and Cost of Gastrointestinal, Liver, and Pancreatic Diseases in the United States: Update 2018. Gastroenterology 156 (1), 254-272. e11. doi:10.1053/j.gastro.2018.08.063

Penning, C., Delemarre, J. B., Bemelman, W. A., Biemond, I., Lamers, C. B., and Masclee, A. A. (2000). Proximal and Distal Gut Hormone Secretion in Slow Transit Constipation. Eur. J. Clin. Invest. 30 (8), 709-714. doi:10.1046/j.13652362.2000.00692.x

Peplowski, M. A., Vegso, A. J., Iablokov, V., Dicay, M., Zaheer, R. S., Renaux, B., et al. (2017). Tumor Necrosis Factor a Decreases Aquaporin 3 Expression in Intestinal Epithelial Cells through Inhibition of Constitutive Transcription. Physiol. Rep. 5 (19), e13451. doi:10.14814/phy2.13451

Peplowski, M. A., Dicay, M., Baggio, C. H., Wysokinski, F., Renaux, B., Hollenberg, M. D., et al. (2018). Interferon Gamma Decreases Intestinal Epithelial Aquaporin 3 Expression through Downregulation of Constitutive Transcription. J. Mol. Med. 96 (10), 1081-1093. doi:10.1007/s00109-0181681-2

Reynaud, Y., Fakhry, J., Fothergill, L., Callaghan, B., Ringuet, M., Hunne, B., et al. (2016). The Chemical Coding of 5-hydroxytryptamine Containing Enteroendocrine Cells in the Mouse Gastrointestinal Tract. Cell Tissue Res 364 (3), 489-497. doi:10.1007/s00441-015-2349-7

Sanders, K. M., Ward, S. M., and Koh, S. D. (2014). Interstitial Cells: Regulators of Smooth Muscle Function. Physiol. Rev. 94 (3), 859-907. doi:10.1152/ physrev.00037.2013

Schaeffer, D. F., Kirsch, R., and Riddell, R. H. (2012). Mast Cells and Intestinal Motility Disorders (Mastocytic Enteritis/colitis). Dig. Dis. Sci. 57 (5), 1118-1121. doi:10.1007/s10620-012-2123-6

Schneider, S., Wright, C. M., and Heuckeroth, R. O. (2019). Unexpected Roles for the Second Brain: Enteric Nervous System as Master Regulator of Bowel Function. Annu. Rev. Physiol. 81, 235-259. doi:10.1146/annurev-physiol021317-121515

Segers, A., Desmet, L., Thijs, T., Verbeke, K., Tack, J., and Depoortere, I. (2019). The Circadian Clock Regulates the Diurnal Levels of Microbial Short-chain Fatty Acids and Their Rhythmic Effects on colon Contractility in Mice. Acta Physiol. 225 (3), e13193. doi:10.1111/apha.13193

Shah, E. D., Kim, H. M., and Schoenfeld, P. (2018). Efficacy and Tolerability of Guanylate Cyclase-C Agonists for Irritable Bowel Syndrome with Constipation and Chronic Idiopathic Constipation: A Systematic Review and Meta-Analysis. Am. J. Gastroenterol. 113 (3), 329-338. doi:10.1038/ajg.2017.495

Silos-Santiago, I., Hannig, G., Eutamene, H., Ustinova, E. E., Bernier, S. G., Ge, P., et al. (2013). Gastrointestinal Pain: Unraveling a Novel Endogenous Pathway through Uroguanylin/guanylate Cyclase-C/cGMP Activation. Pain 154 (9), 1820-1830. doi:10.1016/j.pain.2013.05.044

Sisto, M., Ribatti, D., and Lisi, S. (2019). Aquaporin Water Channels: New Perspectives on the Potential Role in Inflammation. Adv. Protein Chem. Struct. Biol. 116, 311-345. doi:10.1016/bs.apcsb.2018.11.010

Smith, T. K., Park, K. J., and Hennig, G. W. (2014). Colonic Migrating Motor Complexes, High Amplitude Propagating Contractions, Neural Reflexes and the Importance of Neuronal and Mucosal Serotonin. J. Neurogastroenterol Motil. 20 (4), 423-446. doi:10.5056/jnm14092 
Smith-Edwards, K. M., Najjar, S. A., Edwards, B. S., Howard, M. J., Albers, K. M., and Davis, B. M. (2019). Extrinsic Primary Afferent Neurons Link Visceral Pain to Colon Motility through a Spinal Reflex in Mice. Gastroenterology 157 (2), 522-536.e2. doi:10.1053/j.gastro.2019.04.034

Stead, R. H., Dixon, M. F., Bramwell, N. H., Riddell, R. H., and Bienenstock, J. (1989). Mast Cells Are Closely Apposed to Nerves in the Human Gastrointestinal Mucosa. Gastroenterology 97 (3), 575-585. doi:10.1016/ 0016-5085(89)90627-6

Sudo, H., Ozaki, K., Muramatsu, H., Kamei, K., Yogo, K., Cynshi, O., et al. (2007). Mitemcinal (GM-611), an Orally Active Motilin Agonist, Facilitates Defecation in Rabbits and Dogs without Causing Loose Stools. Neurogastroenterol Motil. 19 (4), 318-326. doi:10.1111/j.1365-2982.2006.00885.x

Sundell, K. S., and Sundh, H. (2012). Intestinal Fluid Absorption in Anadromous Salmonids: Importance of Tight Junctions and Aquaporins. Front. Physio. 3, 388. doi:10.3389/fphys.2012.00388

Szurszewski, J. H., Ermilov, L. G., and Miller, S. M. (2002). Prevertebral Ganglia and Intestinofugal Afferent Neurones. Gut 51 (Suppl. 1), i6-i10. doi:10.1136/ gut.51.suppl_1.i6

Tait, C., and Sayuk, G. S. (2021). The Brain-Gut-Microbiotal Axis: A Framework for Understanding Functional GI Illness and Their Therapeutic Interventions. Eur. J. Intern. Med. 84, 1-9. doi:10.1016/j.ejim.2020.12.023

Taniguchi, S., Yano, T., Imaizumi, M., and Manabe, N. (2018). Elobixibat, an Ileal Bile Acid Transporter Inhibitor, Induces Giant Migrating Contractions during Natural Defecation in Conscious Dogs. Neurogastroenterol Motil. 30 (12), e13448. doi:10.1111/nmo.13448

Vijayvargiya, P., and Camilleri, M. (2019). Use of Prucalopride in Adults with Chronic Idiopathic Constipation. Expert Rev. Clin. Pharmacol. 12 (7), 579-589. doi:10.1080/17512433.2019.1620104

Wald, A., Scarpignato, C., Mueller-Lissner, S., Kamm, M. A., Hinkel, U., Helfrich, I., et al. (2008). A Multinational Survey of Prevalence and Patterns of Laxative Use Among Adults with Self-Defined Constipation. Aliment. Pharmacol. Ther. 28 (7), 917-930. doi:10.1111/j.1365-2036.2008.03806.x

Wald, A. (2003). Is Chronic Use of Stimulant Laxatives Harmful to the colon? J. Clin. Gastroenterol. 36 (5), 386-389. doi:10.1097/00004836-20030500000004

Wang, G.-D., Wang, X.-Y., Liu, S., Qu, M., Xia, Y., Needleman, B. J., et al. (2014). Innervation of Enteric Mast Cells by Primary Spinal Afferents in guinea Pig and Human Small Intestine. Am. J. Physiology-Gastrointestinal Liver Physiol. 307 (7), G719-G731. doi:10.1152/ajpgi.00125.2014

Wang, H. L. (2015). Understanding the Pathogenesis of Slow-Transit Constipation: One Step Forward. Dig. Dis. Sci. 60 (8), 2216-2218. doi:10.1007/s10620-0153754-1

Wouters, M. M., Farrugia, G., and Schemann, M. (2007). 5-HT Receptors on Interstitial Cells of Cajal, Smooth Muscle and Enteric Nerves. Neurogastroenterol Motil. 19 (Suppl. 2), 5-12. doi:10.1111/j.13652982.2007.00963.x

Wouters, M. M., Vicario, M., and Santos, J. (2016). The Role of Mast Cells in Functional GI Disorders. Gut 65 (1), 155-168. doi:10.1136/gutjnl-2015-309151

Wright, E. M., and Loo, D. D. F. (2000). Coupling between Na+, Sugar, and Water Transport across the Intestine. Ann. N. Y. Acad. Sci. 915, 54-66. doi:10.1111/ j.1749-6632.2000.tb05223.x
Xu, L., Depoortere, I., Tomasetto, C., Zandecki, M., Tang, M., Timmermans, J.-P., et al. (2005). Evidence for the Presence of Motilin, Ghrelin, and the Motilin and Ghrelin Receptor in Neurons of the Myenteric Plexus. Regul. Peptides 124, 119-125. doi:10.1016/j.regpep.2004.07.022

Yajima, T., Inoue, R., Matsumoto, M., and Yajima, M. (2011). Non-neuronal Release of ACh Plays a Key Role in Secretory Response to Luminal Propionate in Rat colon. J. Physiol. 589 (4), 953-962. doi:10.1113/jphysiol.2010.199976

Yano, J. M., Yu, K., Donaldson, G. P., Shastri, G. G., Ann, P., Ma, L., et al. (2015). Indigenous Bacteria from the Gut Microbiota Regulate Host Serotonin Biosynthesis. Cell 161 (2), 264-276. doi:10.1016/j.cell.2015.02.047

Yarullina, D. R., Shafigullin, M. U., Sakulin, K. A., Arzamastseva, A. A., Shaidullov, I. F., Markelova, M. I., et al. (2020). Characterization of Gut Contractility and Microbiota in Patients with Severe Chronic Constipation. PLoS One 15 (7), e0235985. doi:10.1371/journal.pone.0235985

Zhan, Y., Tang, X., Xu, H., and Tang, S. (2020). Maren Pills Improve Constipation via Regulating AQP3 and NF-kB Signaling Pathway in Slow Transit Constipation In Vitro and In Vivo. Evid. Based Complement. Altern. Med. 2020, 1-12. doi:10.1155/2020/9837384

Zhang, C., Jiang, J., Tian, F., Zhao, J., Zhang, H., Zhai, Q., et al. (2020). Metaanalysis of Randomized Controlled Trials of the Effects of Probiotics on Functional Constipation in Adults. Clin. Nutr. 39 (10), 2960-2969. doi:10.1016/j.clnu.2020.01.005

Zheng, Y.-F., Liu, C.-F., Lai, W.-F., Xiang, Q., Li, Z.-F., Wang, H., et al. (2014). The Laxative Effect of Emodin Is Attributable to Increased Aquaporin 3 Expression in the colon of Mice and HT-29 Cells. Fitoterapia 96, 25-32. doi:10.1016/ j.fitote.2014.04.002

Zhu, F., Xu, S., Zhang, Y., Chen, F., Ji, J., and Xie, G. (2016). Total Glucosides of Paeony Promote Intestinal Motility in Slow Transit Constipation Rats through Amelioration of Interstitial Cells of Cajal. PLoS One 11 (8), e0160398. doi:10.1371/journal.pone.0160398

Zhu, S., Ran, J., Yang, B., and Mei, Z. (2017). Aquaporins in Digestive System. Adv. Exp. Med. Biol. 969, 123-130. doi:10.1007/978-94-024-1057-0_10.1007/97894-024-1057-0_8

Conflict of Interest: The authors declare that the research was conducted in the absence of any commercial or financial relationships that could be construed as a potential conflict of interest.

Publisher's Note: All claims expressed in this article are solely those of the authors and do not necessarily represent those of their affiliated organizations, or those of the publisher, the editors and the reviewers. Any product that may be evaluated in this article, or claim that may be made by its manufacturer, is not guaranteed or endorsed by the publisher.

Copyright $\odot 2021$ Zhao, Chen, Xu, Yue, Fu, Yang, Xing and Tang. This is an openaccess article distributed under the terms of the Creative Commons Attribution License (CC BY). The use, distribution or reproduction in other forums is permitted, provided the original author $(s)$ and the copyright owner(s) are credited and that the original publication in this journal is cited, in accordance with accepted academic practice. No use, distribution or reproduction is permitted which does not comply with these terms. 


\section{GLOSSARY}

5-HT 5-hydroxytryptamine

AC adenylate cyclase

Ach acetylcholine

ANS autonomic nervous system

AQPs aquaporins

ATP adenosine triphosphate

$\mathrm{CaCC} \mathrm{Ca}{ }^{2+}$ activated $\mathrm{Cl}^{-}$channel

cAMP cyclic adenosine monophosphate

CFTR cystic fibrosis transmembrane conductance regulator

cGMP cyclic guanosine monophosphate

CGRP calcitonin gene-related peptide

CNS central nervous system

CREB cAMP response element-binding protein

ECs enterochromaffin cells

EGCs enteric glial cells

$\mathrm{ENaC}$ epithelial sodium channel

ENS enteric nervous system
ExPANs extrinsic primary afferent neurons

GC-C guanylate cyclase-C

$\mathbf{H}_{2} \mathrm{~S}$ hydrogen sulfide

HAPCs high-amplitude propagating contractions

ICCs interstitial cells of Cajal

LPS lipopolysaccharide

NKCC1 $\mathrm{Na}^{+} / \mathrm{K}^{+} / 2 \mathrm{Cl}^{-}$co-transporter

NO nitric oxide

NOS nitric oxide synthase

PDGFRa $^{+}$platelet-derived growth factor receptor $\alpha$-positive

$\mathrm{PGE}_{2}$ prostaglandin $\mathrm{E}_{2}$

PKA protein kinase A

SCFAs short-chain fatty acids

SP substance $P$

TCM Traditional Chinese medicine

TGP Total glucosides of paeony

TNF- $\boldsymbol{\alpha}$ tumor necrosis factor alpha

VIP vasoactive intestinal peptide 